\title{
Explaining the social gradient in long-term sickness absence: a prospective study of Danish employees
}

\author{
Karl Bang Christensen, ${ }^{1}$ Merete Labriola, ${ }^{1}$ Thomas Lund, ${ }^{1}$ Mika Kivimäki ${ }^{2}$
}

${ }^{1}$ National Institute of Occupational Health, Denmark;

${ }^{2}$ Department of Epidemiology and Public Health, University

College London, London, UK and Finnish Institute of Occupational Health, Helsinki, Finland

Correspondence to: Mrs Merete Labriola, National Research Center for the Working Environment, Lersø Parkallé 105 Copenhagen, Denmark, DK2100; mla@ami.dk

Accepted 30 March 2007

\section{ABSTRACT}

Objectives: To identify differences in risk of sickness absence between socioeconomic groups, and to examine to what extent these differences can be explained by health behaviour and work environment factors.

Design, setting and participants: A cohort of 5221 employees in Denmark interviewed in 2000 regarding health behaviours and work environment were followed for 18 months in order to assess their rate of sickness absence exceeding eight consecutive weeks. Based on employment grade, job title and education respondents were classified into five socioeconomic position (SEP) groups. Executive managers and academics were the reference group.

Results: For both genders a social gradient in long-term sickness absence rates was evident. In men, controlling for health behaviours and physical work environment factors reduced rate ratios by $22-57 \%$. Controlling for health behaviours alone reduced rate ratios by $6-13 \%$. In women, controlling for health behaviour reduced rate ratios by $5-18 \%$, and controlling for both health behaviours and physical work environment factors reduced rate ratios by $21-44 \%$. Introducing psychosocial factors reduced the rate ratios further, yielding a reduction of $22-53 \%$ in the fully adjusted model. In both genders, the largest reductions were seen in skilled blue-collar workers and for semi-skilled or unskilled workers (by 58$59 \%$ in men and by $41-53 \%$ in women).

Conclusion: A social gradient in long-term sickness absence was found. Physical work environment explained more of this gradient than health behaviour. Also including psychosocial work environment in the model had no effect in men but a small effect among women.

A social gradient in morbidity and mortality is well demonstrated, but only few studies have examined such gradients in relation to long-term sickness absence. $^{12}$ This is a limitation as long-term sickness absence is emerging as a major public health problem. ${ }^{3}$ We therefore studied differences between socioeconomic position (SEP) groups in the risk of long-term sickness absence and the extent to which these differences were explained by health behaviours and work environment in a contemporary working population.

\section{PARTICIPANTS AND METHODS}

A random sample of Danish employees was interviewed in 2000 as part of the Danish Work Environment Cohort Study (DWECS). ${ }^{4}$ A random population sample of 11437 people aged 18-69 were invited to participate, and responses from 8583 were ascertained (response rate $75 \%$ ). Of these, 5366 were employees and 5221 provided information about all health behaviour and work environment factors. Data on long-term sickness absence, defined as receiving sickness absence compensation for eight consecutive weeks during 18 months of follow-up, were obtained by a linkage to a national register of social transfer payments (DREAM). Eight weeks was chosen as the cut-off point, as after this time the case-managing municipal authorities are informed that an individual is on sick leave and the sick leave is recorded to the register of social transfer payments.

Based on employment grade, job title and education respondents were classified into five SEP groups; I: executive managers and/or academics (261 women, 558 men), II: middle managers and/or 3-4 years of further education (517 women, 299 men), III: other white-collar workers (1113 women, 660 men), IV: skilled blue-collar workers (189 women, 521 men), and $\mathrm{V}$ : semi-skilled or unskilled workers (482 women, 621 men).

Employees provided data on age, gender and school education ( 9 years or less; 10 years; high school). Family status was categorised using two variables: number of children living at home (none; one child; two children; three or more children) and cohabitation status (living with a partner, yes/no).

Regarding smoking status the population was divided into non-smokers, ex-smokers, moderate smokers (less than 15 cigarettes/day) and heavy smokers (15 cigarettes/day or more). Categories of alcohol consumption were non-drinkers, moderate drinkers and heavy drinkers consuming more than 14 (for women) or 21 (for men) weekly units of alcohol (cut-off points chosen in accordance with Danish National Board of Health guidelines). Body mass index $\left(\mathrm{kg} / \mathrm{m}^{2}\right)$ was categorised according to the standardised classification of the National Institutes of Health using four categories: underweight (<18.5), normal (18.5-24.9), overweight (25-29.9) and obesity (>30). Leisure-time physical activity was measured using a single item (responses: less than 2 hours a week; 2-4 hours a week; more than 4 hours a week or strenuous; or more than 4 hours a week and strenuous).

Physical work environment factors were assessed using 11 questions, which were combined into five indices. Three measured uncomfortable work positions: extreme bending or twisting of the neck or back, work with arms lifted or hands twisted and working mainly standing or squatting; and two assessed physical workload in terms of lifting or carrying loads and pushing or pulling loads. ${ }^{5}$

The psychosocial work environment factors included decision authority, skill discretion, quantitative demands, support, intensive quantitative demands, ${ }^{6}$ corresponding closely to those used in previous studies. ${ }^{12}$ All work environment factors were used as continuous variables. Levels for physical and psychosocial exposures in the five SEP groups are shown in table 1 . 
Table 1 Exposure levels for the five socioeconomic position groups

\begin{tabular}{|c|c|c|c|c|c|}
\hline Exposure variables & $\begin{array}{l}\text { I Executive managers/ } \\
\text { academics }\end{array}$ & $\begin{array}{l}\text { II Middle managers/3-4 years } \\
\text { further education }\end{array}$ & $\begin{array}{l}\text { III Other white collar } \\
\text { workers }\end{array}$ & $\begin{array}{l}\text { IV Skilled blue-collar } \\
\text { workers }\end{array}$ & $\begin{array}{l}\text { V Semiskilled and } \\
\text { unskilled workers }\end{array}$ \\
\hline $\begin{array}{l}\text { Working mainly standing or } \\
\text { squatting }\end{array}$ & $8.4(11.6)$ & $20.3(16.0)$ & $18.6(18.9)$ & $38.0(20.5)$ & $33.3(20.4)$ \\
\hline Lifting or carrying loads & $5.2(10.1)$ & $13.3(17.8)$ & $13.6(18.1)$ & $26.2(22.2)$ & $25.0(20.8)$ \\
\hline Decision authority & $66.1(22.5)$ & $57.3(23.8)$ & $47.6(25.5)$ & $45.3(24.7)$ & $34.6(25.6)$ \\
\hline Skill discretion & $85.4(12.4)$ & $82.9(13.6)$ & $75.6(16.3)$ & $73.8(16.7)$ & $58.8(22.6)$ \\
\hline Quantitative demands & $51.9(20.6)$ & $42.9(21.4)$ & $37.0(21.1)$ & $35.1(19.3)$ & $29.7(20.1)$ \\
\hline Support & $67.0(23.8)$ & $69.1(23.9)$ & $70.2(24.1)$ & $67.3(24.8)$ & $66.2(27.7)$ \\
\hline Intensive quantitative demands & $54.6(27.0)$ & $54.3(26.8)$ & $54.2(26.5)$ & $52.5(26.3)$ & $50.8(29.6)$ \\
\hline
\end{tabular}

Exposure levels for the five socioeconomic position groups. Mean score (SD) on indices ranging from 0 to 100 , where 0 corresponds to the lowest and 100 corresponds to the highest level.

Poisson regression models were used to calculate rate ratios and 95\% confidence intervals. Those receiving another social benefitfor example, those on maternity leave, were not considered to be under risk in that period. Those who emigrated, retired or died were considered to be at risk until the time of emigration, retirement or death. Analyses were done using SAS.

The analysis was conducted in steps: firstly, rate ratios were adjusted for age and family status; next, rate ratios were adjusted for age, family status and health behaviour. In a third step rate ratios were adjusted for age, family status, health behaviour and physical work environment factors; and, finally, rate ratios were adjusted for age, family status, health behaviour, physical and psychosocial work environment factors.

In order to study the impact on the overall social gradient analyses in which the SEP group variable was added as a linear term were also considered.

\section{RESULTS}

The rates of long-term sickness absence in the study population in the age groups $-20,21-30,31-40,41-50,51-60$ and $61+$ were

Table 2 Rate ratios (RR) and 95\% confidence intervals (Cl) for onset of long-term sickness absence during 18 months of follow-up (absolute and relative change in rate ratios when adjusting)

\begin{tabular}{|c|c|c|c|c|c|c|}
\hline \multirow[b]{2}{*}{ Model } & \multicolumn{3}{|l|}{ Men } & \multicolumn{3}{|c|}{ Women } \\
\hline & $\mathbf{R R}$ & $(95 \% \mathrm{CI})$ & Change & $\mathbf{R R}$ & $(95 \% \mathrm{CI})$ & Change \\
\hline \multicolumn{7}{|l|}{ Adjusted for age and family status } \\
\hline I Executive managers/academics & 1.00 & - & & 1.00 & - & \\
\hline II Middle managers/3-4 years further education & 2.04 & (0.93 to 4.47$)$ & & 3.02 & (1.18 to 7.78$)$ & \\
\hline III Other white-collar workers & 2.67 & $(1.39$ to 5.13$)$ & & 4.34 & (1.77 to 10.69$)$ & \\
\hline IV Skilled blue-collar workers & 3.56 & $(1.85$ to 6.85$)$ & & 3.47 & (1.21 to 10.01$)$ & \\
\hline V Semiskilled and unskilled workers & 4.22 & (2.23 to 7.97$)$ & & 5.80 & (2.28 to 14.75$)$ & \\
\hline SEP as a linear term & 1.37 & (1.21 to 1.55$)$ & & 1.30 & (1.14 to 1.47$)$ & \\
\hline \multicolumn{7}{|c|}{ Adjusted for age, family status and health behaviour } \\
\hline I Executive managers/academics & 1.00 & - & & 1.00 & - & \\
\hline II Middle managers/3-4 years further education & 1.89 & (0.86 to 4.15$)$ & $0.15(7 \%)$ & 2.87 & (1.11 to 7.38$)$ & $0.15(5 \%)$ \\
\hline III Other white-collar workers & 2.50 & (1.30 to 4.84$)$ & $0.17(6 \%)$ & 3.88 & (1.57 to 9.58$)$ & $0.46(11 \%)$ \\
\hline IV Skilled blue-collar workers & 3.25 & $(1.68$ to 6.31$)$ & $0.31(9 \%)$ & 3.10 & $(1.07$ to 8.96$)$ & $0.37(11 \%)$ \\
\hline V Semiskilled and unskilled workers & 3.66 & (1.91 to 7.03 ) & $0.56(13 \%)$ & 4.73 & (1.84 to 12.15 ) & $1.07(18 \%)$ \\
\hline SEP as a linear term & 1.33 & (1.17 to 1.51$)$ & $0.04(3 \%)$ & 1.24 & (1.09 to 1.41$)$ & $0.06(5 \%)$ \\
\hline \multicolumn{7}{|c|}{$\begin{array}{l}\text { Adjusted for age, family status, health behaviour and } \\
\text { physical work environment }\end{array}$} \\
\hline I Executive managers/academics & 1.00 & - & & 1.00 & - & \\
\hline II Middle managers/3-4 years further education & 1.59 & $(0.72$ to 3.53$)$ & $0.45(22 \%)$ & 2.40 & (0.92 to 6.24$)$ & $0.62(21 \%)$ \\
\hline III Other white-collar workers & 1.85 & $(0.94$ to 3.64$)$ & $0.82(31 \%)$ & 3.24 & $(1.30$ to 8.04$)$ & $1.10(25 \%)$ \\
\hline IV Skilled blue-collar workers & 1.58 & $(0.75$ to 3.33$)$ & $1.98(56 \%)$ & 2.18 & $(0.74$ to 6.45$)$ & $1.30(37 \%)$ \\
\hline V Semiskilled and unskilled workers & 1.83 & $(0.90$ to 3.73$)$ & $2.39(57 \%)$ & 3.24 & $(1.23$ to 8.56$)$ & $2.56(44 \%)$ \\
\hline SEP as a linear term & 1.10 & (0.95 to 1.28$)$ & $0.27(20 \%)$ & 1.14 & (0.99 to 1.32$)$ & $0.16(12 \%)$ \\
\hline \multicolumn{7}{|c|}{$\begin{array}{l}\text { Adjusted for age, family status, health behaviour, physical } \\
\text { and psychosocial work environment }\end{array}$} \\
\hline I Executive managers/academics & 1.00 & - & & 1.00 & - & \\
\hline II Middle managers/3-4 years further education & 1.60 & $(0.72$ to 3.56$)$ & $0.44(22 \%)$ & 2.37 & (0.91 to 6.18$)$ & $0.65(22 \%)$ \\
\hline III Other white-collar workers & 1.76 & $(0.88$ to 3.54$)$ & $0.91(34 \%)$ & 3.01 & (1.19 to 7.59$)$ & $1.33(38 \%)$ \\
\hline IV Skilled blue-collar workers & 1.46 & $(0.68$ to 3.16$)$ & $2.10(59 \%)$ & 2.06 & (0.69 to 6.17$)$ & $1.42(41 \%)$ \\
\hline V Semiskilled and unskilled workers & 1.77 & (0.83 to 3.79$)$ & $2.45(58 \%)$ & 2.76 & $(1.00$ to 7.65$)$ & $3.04(52 \%)$ \\
\hline SEP as a linear term & 1.09 & (0.93 to 1.29$)$ & $0.28(20 \%)$ & 1.09 & (0.93 to 1.28$)$ & $0.21(16 \%)$ \\
\hline
\end{tabular}

\footnotetext{
SEP, socioeconomic position.
} 
2.1, 4.4, 4.6, 5.8, 5.5, 1.9 per 100 person years, respectively. The cumulative incidence of long-term sickness absence during 18 months of follow-up showed a strong social gradient ranging from $3.1 \%$ (group I) to $11.2 \%$ (group V) for women and from $2.5 \%$ (group I) to $9.2 \%$ (group V) for men.

Table 2 shows rate ratios for the onset of sickness absence for socioeconomic position groups II to $\mathrm{V}$ compared with group I by gender.

For both men and women rate ratios adjusted for age and family status were similar to crude rate ratios (not shown). In men the rate ratios were higher in lower SEP groups and the differences were statistically significant (likelihood ratio test: $p<0.0001)$. In women the differences in the rate ratios were also statistically significant (likelihood ratio test: $p<0.0001$ ), but rates were higher in women belonging to SEP group III than in those women belonging to SEP group IV. Since occupations in SEP III tend to be either female-dominated or male-dominated (nursing and teaching being common occupations for women and skilled workers for men), one explanation could be that female-dominated groups tend to develop more lenient norms and standards with regard to sickness absence than are found in more male-dominated contexts.

In men, SEP groups III, IV and V had significantly higher rate of long-term sickness absence, rate ratios adjusted for age and family status ranged from 2.67 to 4.22 . Further adjustment for health behaviour reduced these rate ratios by $6-13 \%$, the largest change occurred for SEP group $\mathrm{V}$ where the rate ratio dropped to 3.66. The difference between rate ratios remained statistically significant (likelihood ratio test: $p=0.0003$ ). Further adjusting for physical work environment factors yielded rate ratios that were reduced by $31-57 \%$ compared to those adjusted for age and family status. Again the largest changes were seen for SEP group IV, where the rate ratio was 1.58 and SEP group V where the rate ratio was 1.83 . The difference between rate ratios was no longer statistically significant (likelihood ratio test: $\mathrm{p}=0.4134$ ). Introducing psychosocial work environment factors into the analysis yielded no substantial change in rate ratios or in the likelihood ratio test of equality $(p=0.4959)$. The pattern was similar for the overall estimate of the social gradient obtained by introducing SEP as a linear term.

In women SEP groups II-V had significantly higher absence rate than SEP group I. Rate ratios adjusted for age and family status ranged from 3.02 to 5.80 . Adjusting for health behaviour reduced these rate ratios by $5-18 \%$, the largest change occurring for SEP group $\mathrm{V}$ where the rate ratio dropped to 4.73 . The difference between rate ratios remained statistically significant (likelihood ratio test: $p=0.0017)$. Further adjusting for physical work environment factors yielded rate ratios that were reduced by $21-$ $44 \%$ compared to those adjusted for gender and family status, again the largest change was for SEP groups IV and V. For SEP group IV the initial rate ratio of 3.47 was reduced by $37 \%$ to 2.18 and for SEP group $\mathrm{V}$ the initial rate ratio of 5.80 was reduced by $44 \%$ to 3.24 . The difference between rate ratios was borderline significant (likelihood ratio test: $p=0.0258$ ). Introducing psychosocial factors reduced the rate ratios further, yielding a reduction of $22-53 \%$ in the fully adjusted model. The difference between rate ratios was no longer statistically significant (likelihood ratio test: $p=0.0780$ ). Again, the pattern was similar for the overall estimate of the social gradient obtained by introducing SEP as a linear term.

Beyond the demand-control-support model several other psychosocial factors (emotional demands, demands of hiding emotions, job insecurity, management quality, role conflicts, reward, meaning in work, predictability and conflicts at work)

\section{What is already known on this subject}

Sickness absence is distributed unevenly across socioeconomic position groups.

\section{What this study adds}

- Differences in long-term sickness absence risk between socioeconomic position groups are larger among men than among women

- Differences in health behaviours and work environment explain a large part of the inequalities in long-term sickness absence risk between socioeconomic position groups.

- Physical work environment factors had the biggest impact on the social gradient. Including psychosocial work environment in the model had no effect in men but a small effect among women

\section{Policy implications}

Successful interventions reducing health risk behaviours and adverse work conditions may have the largest potential gain among skilled, semi-skilled and unskilled blue-collar workers.

were studied, but introducing these did not further reduce the social gradient (results not shown).

\section{CONCLUSIONS}

A social gradient in long-term sickness absence was evident. In previous studies the explanatory factors accounted for part of the social gradient in sickness absence. ${ }^{12}$ The present study used data from a general working population with a full range of socioeconomic positions rather than from specific workplace samples and a more comprehensive assessment of physical work environment and health behaviours. In general, physical work environment factors explained more of this gradient than health behaviours and these factors in combination explained a large part of the differences in long-term sickness absence between SEP groups. The effect of introducing psychosocial factors into the most adjusted model led to a relatively small additional reduction in the rate ratios, the effect being larger in women than in men.

Competing interests: None.

\section{REFERENCES}

1. Melchior M, Krieger N, Kawachi I, et al. Work factors and occupational class disparities in sickness absence: findings from the GAZEL Cohort Study. Am J Public Health 2005;95:1206-12

2. North F, Syme SL, Feeney A, et al. Explaining socioeconomic differences in sickness absence: the Whitehall II Study. BMJ 1993;306:361-6.

3. Henderson $\mathbf{M}$, Glozier N, Elliott $\mathrm{KH}$. Long term sickness absence: is caused by common conditions and needs managing. BMJ 2005;330:802-3

4. Burr H, Bjorner JB, Kristensen TS, et al. Trends in the Danish work environment in 1990-2000 and their associations with labor-force changes. Scand J Work Environ Health 2003;29:270-9.

5. Lund T, Labriola M, Christensen KB, et al. Physical work environment risk factors for long term sickness: prospective findings among a cohort of 5357 employees in Denmark. BMJ 2006:332:449-52.

6. Lund T, Labriola M, Christensen KB, et al. Psychosocial work environment exposures as risk factors for long-term sickness absence among Danish employees: results from DWECS/DREAM. J Occup Environ Med 2005;47:1141-7.

7. Mastekaasa A. Sickness absence in female- and male-dominated occupations and workplaces. Soc Sci Med 2005;60:2261-72. 